\title{
EDITORIAL
}

\section{Bioequivalence of inhaled drugs}

\author{
E. Derom, R. Pauwels
}

It is generally accepted that inhalation therapy is the most effective way to treat patients with asthma or chronic obstructive pulmonary disease (COPD). Indeed, inhalation of relatively small doses of drug not only results in high, local concentrations in the airways - the site of the disease - but minimizes the risk for side-effects by decreasing the amount of drug reaching the systemic circulation. For more than 30 yrs, chlorofluorocarbondriven metered-dose inhalers have been considered as the device of choice for delivery of aerosolized drugs. They have been used in the numerous clinical trials which have been conducted over the last two decades in order to establish the appropriate dose regimens of inhaled $\beta_{2}$-agonists, anticholinergics or corticosteroids in patients with mild, moderate, or severe asthma or COPD [1].

Two events have recently contributed to the development of alternative inhalation devices: the requirements to substitute chlorofluorocarbon (CFC) propellants with suitable alternatives [2]; and the expiry of patent for a number of inhaled medications, such as salbutamol and beclomethasone. In this context, generic CFC inhalers and new delivery systems, such as dry powder or CFCfree, pressurized inhalers, have been introduced or are currently under development.

For many years, standardized methods have been used to demonstrate bioequivalence of orally or parenterally administered drugs. In contrast, generally-accepted, standardized guidelines to establish the bioequivalence of inhaled drugs were not available. New methods to compare bioequivalence from metered-dose inhalers are now being developed in the light of requirements of public health authorities concerning the rapidly increasing number of inhalation devices. The usefulness of such methods is illustrated in the study by MILLER and BRIGHT [3], published in the present issue of the European Respiratory Journal. Their study reveals a $36 \%$ difference in output between three generic inhalers, currently available in the UK, if used in conjunction with a large volume spacer.

\section{Differences in bioequivalence between inhalers}

The study by MiLler and BRIGHT [3] addresses the compatibility between different metered-dose inhalers

Correspondence: E. Derom, Dept of Respiratory Diseases, University Hospital, De Pintelaan 185, B-9000 Gent, Belgium. and different large-volume spacers in general, and the degree to which different combinations of spacer and metered-dose inhaler may affect spray kinetics in general, and adequate delivery to the airways in particular. In this area, much remains to be investigated; however, it has been reported that particle size distribution and pulmonary deposition may differ markedly, when delivered through different spacers [4-7]. Whether differences in static charge on the inner wall of the spacer [8] or its style and design are the most important determinants remains to be investigated. Interestingly, the study by Miller and BRIGHT [3] also demonstrates that different drugs can behave differently when delivered through the same spacer. This suggests that differences in propellant vapour pressure, valve aperture, concentration of drug, solvent, and surfactant may all influence plume geometry and drug deposition on the wall of the spacer. All of these factors may, thus, profoundly modify the passage of the aerosolized drug through the spacer towards the airways.

Miller and BRIGHT [3] did not investigate whether their reported $36 \%$ difference in output yielded a suboptimal response to therapy, nor did they assess the variability between the dose released at each actuation. Nevertheless, their data suggest that substitution of one device with another might not necessarily result in an equivalent therapy. Other investigators, however, have examined the consequences of alterations in drug release or pulmonary deposition in terms of clinical effects. From the relationship between submaximal doses of an inhaled $\beta_{2}$-agonist and its bronchodilating effect, it could be predicted that the existence of a small variability might be clinically significant [9]. Indeed, BLAKE et al. [10] recently demonstrated that failure to prime a newly marketed generic CFC-inhaler resulted in a bronchodilator response that was $19 \%$ less than that obtained with the reference product, and with the generic inhaler after priming.

If the amount delivered by the generic inhaler was obviously the reason for the observed difference in that trial, other, more experimental studies have pointed out that the characteristics of the aerosol generated by the device are another critical determinant of the therapeutic effect. Indeed, a given amount of terbutaline, inhaled from different versions of a dry powder inhaler, resulted in a greater bronchodilator response, provided that the concentration of particles of $<5 \mu \mathrm{m}$ in the aerosol was greater [11]. Such differences may be attributed to differences in particle penetration into the airways, which 
appear to be critically determined by distribution of particle geometry [12]. However, it should be noted that for most drugs the ideal particle size and the optimal site of the tracheobronchial tree - central airways versus peripheral airways - to which the drug should be targeted remains to be established. Moreover, there is also a distinct possibility that the optimal particle deposition site might differ between different drugs. Only a few data dealing with the ideal particle size and site of deposition for each of the currently used drugs have so far been published [13].

Other investigators have pointed out that pulmonary deposition of either budesonide or terbutaline from the recently developed multi-dose dry powder inhaler Turbuhaler ${ }^{\circledR}$ is approximately $20 \%$ of the nominal dose, whereas that from the corresponding CFC-metered dose inhaler averages $10 \%[14,15]$. Interestingly, there is now convincing evidence that switching to Turbuhaler ${ }^{\circledR}$ and reducing the dose by approximately $50 \%$ may result in a comparable degree of asthma control and bronchodilating effect [16]. Conversely, other dry powder inhalers have performed less well than their CFC counterparts, both with respect to pulmonary deposition and to therapeutic effect [17].

\section{Assessment of bioequivalence of inhaled drugs}

These studies, as well as the study reported in the present issue of the Journal [3], underline the need for standardized criteria to determine the exact therapeutic equivalence of drugs generated by the newly developed inhalers in comparison with presently established compounds for marketing authorization. Indeed, it is now evident that the design of the inhaler and its content define variables such as the amount of drug released, the characteristics of the aerosol, and - at least for some of them - the maximal inhalation flow rate. All of these variables may not only greatly influence pulmonary deposition, but will undoubtedly affect their therapeutic action. This recently prompted the British Association for Lung Research to issue a number of "Recommendations for Determining Equivalence of Inhaled Medications" [18]. According to these recommendations, bioequivalence of inhaled medication should be based both on short- and long-term clinical studies, pharmacodynamic and pharmacokinetic assessments, in vitro studies, scintigraphic investigations. They also advocate that comparative studies should be conducted with and without spacer. Although this consensus statement tends to minimize the relevance of pharmacokinetic studies, which have made a substantial contribution to a better understanding of pulmonary deposition and therapeutic equivalence of inhaled drugs $[14,19,20]$, it has nevertheless the merit of being of great help to structure the approach of the many problems encountered with the steadily growing numbers of inhalers. Interestingly, other agencies, such as the "American Food and Drug Administration" and the "Canadian Bureau of Human Prescription Drugs" are also developing guidelines for the bioequivalence of inhaled drugs.

\section{Clinical relevance of bioequivalence studies}

Bioequivalence of inhaled drugs is highly relevant to the clinician currently prescribing inhalation therapy to pulmonary patients. However, factors other than bioequivalence should be taken into account when making a final decision with respect to the preparation which should be prescribed. If ecological and economic factors deserve some attention, the clinician should also focus his attention towards the preparation - the inhaler as well as to the drug it contains - with the highest therapeutic response and minimal systemic effects. It is generally accepted that the magnitude of the therapeutic effect will be dependent on the amount reaching the conducting airways. Conversely, the systemic bioavailability is determined mainly by absorption across the pulmonary epithelium into the pulmonary vascular bed (drug deposited in the conducting airways and alveoli) and, to a lesser extent, by extrapulmonary (gastrointestinal) absorption, unless the mouth is thoroughly rinsed [21, 22].

In the light of the increasing concern about potential systemic effects of inhaled corticosteroids [22, 23], the "ideal inhaler" should: 1) contain a corticosteroid which is not absorbed from the gastrointestinal tract, and which is either not absorbed from the airways or is inactivated or cleared from the circulation as quickly and as completely as possible; and 2) should produce an aerosol characterized by maximal deposition in the conducting airways and minimal deposition at oropharyngeal and alveolar level.

\section{References}

1. International Consensus Report on Diagnosis and Treatment of Asthma. National Heart, Lung and Blood Institute, National Institutes of Health, Bethseda, Maryland 20892. Publication No. 92-3091. Eur Respir J 1992; 5: 601-641.

2. Newman SP. Metered-dose pressurized aerosols and the ozone layer. Eur Respir J 1990; 3: 495-497.

3. Miller RM, Bright P. Differences in output from corticosteroid inhalers used with a volumatic spacer. Eur Respir J 1995; 8: 1637-1638.

4. O'Callaghan C. Particle size of beclomethasone dipropionate produced by two nebulisers and two spacing devices. Thorax 1993; 48: 603-606.

5. Gallard L, Hall G, Qualie JM. The deposition of terbutaline on aerosol spacer devices. Pharmaceut J 1993; 251: R47.

6. Everard ML, Clarke AR, Milner AD. Drug delivery from holding chambers with attached face-mask. Arch Dis Child 1992; 67: 580-585.

7. Hindle M, Chrystyn H. Nebuhaler and volumatic improve pulmonary delivery. Arch Dis Child 1992; 67: 580585.

8. O'Callaghan C, Lynch J, Cant M, Robertson C. Improvement in sodium cromoglycate delivery from a spacer device by use of antistatic lining, immediate inhalation, and avoiding multiple actuations of drug. Thorax 1993; 48: 603-606.

9. Lee MG, Ireland DS, Weir PJ, Dwyer PJ. Comparison of salbutamol inhalers available in the United Kingdom. Int J Pharm Prac 1993; 2: 172-175. 
10. Blake KV, Harman E, Hendeles L. Evaluation of a generic albuterol metered-dose inhaler: importance of priming the MDI. Ann Allergy 1992; 68: 169-174.

11. Persson G, Wirén JE. The bronchodilator response from inhaled terbutaline is influenced by the mass of small particles: a study on a dry powder inhaler (Turbuhaler®). Eur Respir J 1989; 2: 253-256.

12. Martonen TB, Ratz I. Deposition patterns of polydisperse aerosols within human lungs. J Aerosol Med 1993; 6: $271-274$

13. Johnson MA, Newman SP, Bloom R, Talaee N, Clarke SW. Delivery of albuterol and ipratropium bromide from two nebulizer systems in chronic stable asthma. Chest 1989; 96: 1-10.

14. Borgström L, Derom E, Ståhl E, Wåhlin-Boll E, Pauwels $R$. The inhalation device influences lung depostion and bronchodilating effect of terbutaline. Am J Respir Crit Care Med 1995; (in press).

15. Thorsson L, Edsbäcker S, Conradson T-B. Lung deposition of budesonide from Turbuhaler ${ }^{\circledR}$ is twice that from a pressurized metered-dose inhaler P-MDI. Eur Respir J 1994; 7: 1839-1844.

16. Agertoft L, Pedersen S. Importance of the inhalation device on the effect of budesonide. Arch Dis Child 1993; 69: 130-133.
17. Zainudin BMZ, Biddiscombe M, Tolfree SEJ, Short M, Spiro SG. Comparison of bronchodilator responses and deposition patterns of salbutamol inhaled from a pressurized metered-dose inhaler, as a dry powder, and as a nebulised solution. Thorax 1990; 45: 469-473.

18. Rogers DF, Ganderton D. Determining equivalence of inhaled medications. Workshop report. Resp Med 1995; 89: 253-261.

19. Borgström L, Nilsson M. A method for determination of the absolute pulmonary bioavailability of inhaled drugs: terbutaline. Pharmac Res 1990; 7: 1068-1070.

20. Borgström L, Newman S, Weisz A, Morén F. Pulmonary deposition of inhaled terbutaline: comparison of scanning gamma camera and urinary excretion methods. Pharm Sci 1992; 81: 753-755.

21. Lipworth BJ. New perspectives on inhaled drug delivery and systemic bioactivity. Thorax 1995; 50: 105110.

22. Barnes PJ, Pedersen S. Efficacy and safety of inhaled corticosteroids in asthma. Am Rev Respir Dis 1993; 148: S1-S26.

23. Doull IJM, Freezer NJ, Holgate ST. Growth of prepubertal children with mild asthma treated with inhaled beclomethasone diproprionate. Am J Respir Crit Care Med 1995; 151: 1705-1709. 